\section{Zahlen des Monats}

\section{Sprechstunde beim Roboter}

Anscheinend gehen die Deutschen sehr weit, wenn es um ihre Gesundheit geht: Laut einer Umfrage der Schwenninger Krankenkasse (SKK), für die 1.000 Bundesbürger befragt wurden, würde mehr als jeder dritte Bundesbürger einen ihm unbekannten Arzt per Video konsultieren. 30 Prozent zeigen sich offen für die medizinische $\mathrm{Be}$ handlung durch einen Roboter. Immerhin: 90 Prozent der Deutschen legen laut SKK weiterhin großen Wert auf ein ausführliches Gespräch mit dem Arzt ihres Vertrauens und den persönlichen Vor-Ort-Kontakt.

\section{Zahnprobleme bei Junkies}

Im Durchschnitt haben Drogenabhängige etwa 3,5 Zähne weniger, ein erhöhtes Karies- sowie Zahnverlustrisiko und neigen eher zu parodontalen Erkrankungen. So das Ergebnis einer Studie der University of Queensland. Demnach trägt neben dem Konsum von Kokain, Crystal Meth oder Cannabis auch der ungesunde Lebensstil wie unregelmäßige Zahnpflege, Heißhungerattacken und Mangelernährung zum Verfall von Zähnen und Mundgesundheit bei. Zahnärzte nehmen zukünftig eine tragende Rolle ein. So kann ein Zahnarzt die Spuren von Drogen an den Zähnen feststellen, aufklären und vor den Folgen und Risiken des Drogenkonsums warnen.

\section{Krankheit bei Unzufriedenheit}

Menschen, die sich selbst als unglücklich einschätzen, sind unzufriedener mit ihrer Gesundheit und häufiger krank. Dies hat eine Umfrage des Bundesverbandes der Arzneimittel-Hersteller ergeben. Demnach sind nur 18 Prozent der mit ihrem Leben unzufriedenen Menschen mit ihrer Gesundheit zufrieden. Bei denjenigen mit durchschnittlicher Stimmung schätzen hingegen 46 Prozent die eigene Gesundheit als positiv ein, und von den rundum Glücklichen sind 62 Prozent zufrieden mit ihrem Gesundheitszustand. Menschen, die sich selbst als glücklich bezeichnen, hatten 10,8 Krankheitstage im Jahr, die „weniger Glücklichen“ waren im Schnitt 50,7 Tage krank. mar

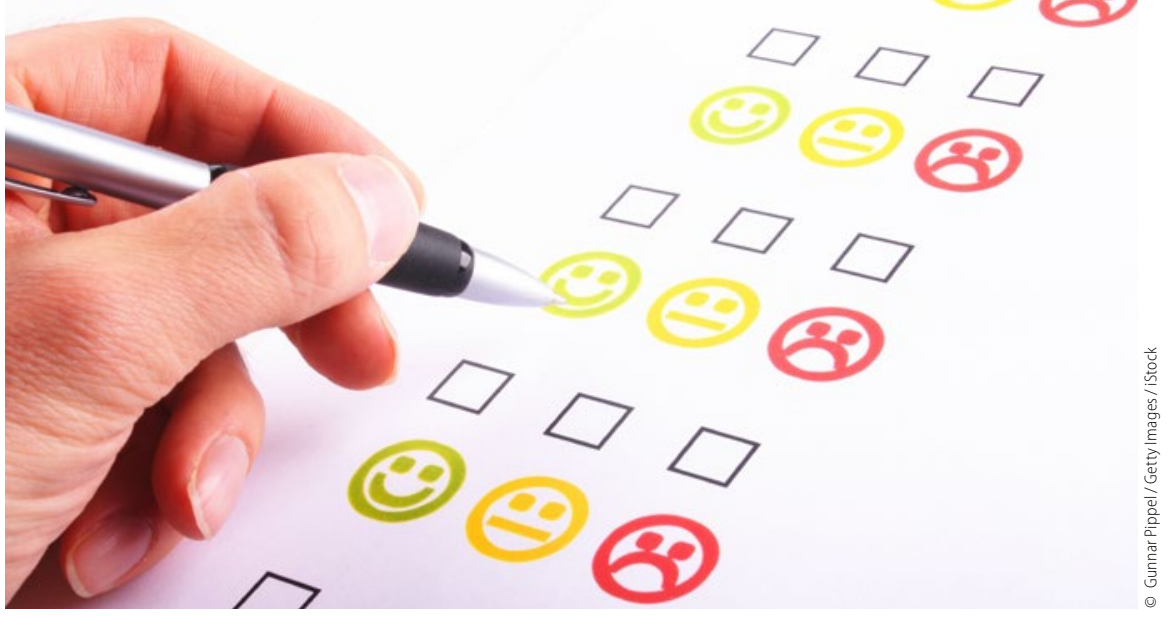

Zwischenergebnisse aus Testregion Nordwest ausreichend

\title{
Gematik lässt Testlauf im Südosten platzen
}

Die Gesellschaft für Telematikanwendungen der Gesundheitskarte (Gematik) hat den geplanten Testlauf zum Abgleich der Versichertenstammdaten in Bayern und Sachsen abgesagt. Dies hat die Ärzte Zeitung auf Nachfrage bei der Gematik Mitte April vermeldet.

Demnach lässt die Gematik den Online-Testlauf in der zweiten Region ausfallen, da die seit November vergangenen Jahres andauernden Tests in der Region Nordwest (Nordrhein-Westfalen, Rheinland-Pfalz, Schleswig-Holstein) bereits Zwischenergebnisse liefern. „Auf Grundlage des bisherigen Verlaufs in dieser Testregion ist davon auszugehen, dass ausreichend signifikante Ergebnisse zum Abschluss der Erprobung vorliegen werden", heißt es von Seiten der Gematik. Diese Ergebnisse seien für die Gesell- schafter Entscheidungsgrundlage, um über den Start des bundesweiten OnlineProduktivbetriebs zu entscheiden.

Der Zeitplan für den Aufbau der Telematikinfrastruktur geriet in der Vergangenheit immer wieder durcheinander. Laut E-Health-Gesetz soll der bundesweite Rollout zur Telematikinfrastruktur ab 1. Juli beginnen. Bis Mitte 2018 muss das Stammdatenmanagement, also die Online-Prüfung und Aktualisierung von Versichertenstammdaten, in allen Praxen flächendeckend eingeführt werden. Wenn die Spitzenorganisationen der Leistungserbringer und Kostenträger die gesetzlich festgeschriebenen Fristen nicht einhalten, werden Haushaltsmittel gekürzt. Außerdem drohen Ärzten und Zahnärzten Vergütungsabschläge.

cas

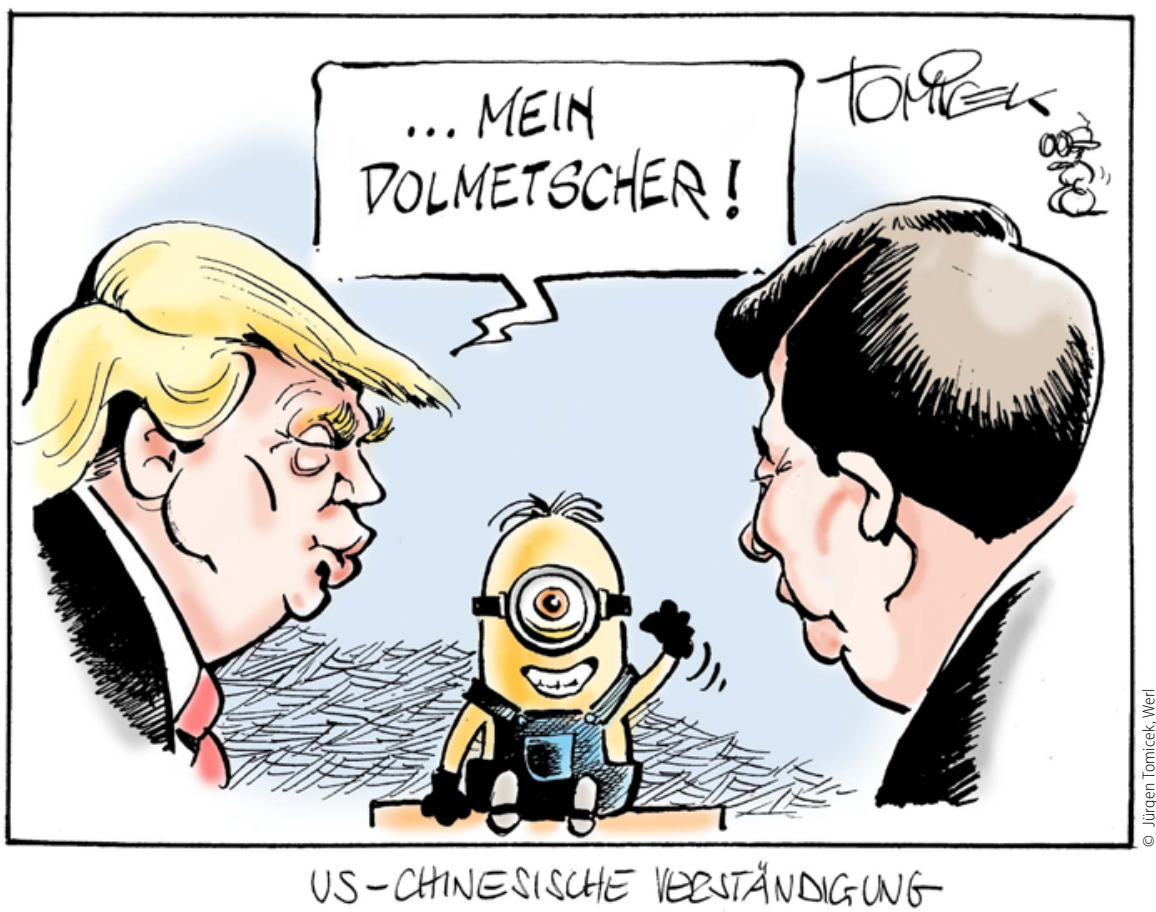

